\title{
Differential mRNA expression of genes in the porcine adrenal gland associated with psychosocial stress
}

\author{
Eduard Muráni ${ }^{1}$, Siriluck Ponsuksili ${ }^{2}$, Richard B D’Eath ${ }^{3}$, Simon P Turner ${ }^{3}$, Gary Evans ${ }^{4}$, \\ Ludger Thölking ${ }^{5}$, Esra Kurt ${ }^{6}$, Ronald Klont ${ }^{7}$, Aline Foury ${ }^{8}$, Pierre Mormède ${ }^{8}$ and \\ Klaus Wimmers ${ }^{1}$ \\ ${ }^{1}$ Research Unit 'Molecular Biology' and ${ }^{2}$ Research Group 'Functional Genomics', Leibniz Institute for Farm Animal Biology (FBN), Wilhelm-Stahl-Allee 2, \\ D-18196 Dummerstorf, Germany \\ ${ }^{3}$ Sustainable Livestock Systems, SAC, West Mains Road, Edinburgh, EH9 3JG, UK \\ ${ }^{4}$ PIC UK, 2 Kingston Business Park, Kingston Bagpuize, Oxfordshire, OX13 5FE, UK \\ ${ }^{5}$ PIC Germany, PIC Deutschland GmbH, Ratsteich 31, 24837 Schleswig, Germany \\ ${ }^{6}$ Optimeter, Oyak sitesi 1.kisim 11b blok da:4, Sefakoy, Istanbul \\ ${ }^{7}$ Vion Food Group, Boseind 10, 5281 RM Boxtel Postbus1, 5280 AA Boxtel, Netherlands \\ ${ }^{8}$ Université Victor Segalen Bordeaux 2, PsyNuGen, UMR1286 INRA, 33076 Bordeaux, France \\ (Correspondence should be addressed to K Wimmers; Email: wimmers@fbn-dummerstorf.de)
}

\begin{abstract}
To gain insight into the adrenal stress response, we analysed differential mRNA expression of genes associated with psychosocial stress in the pig (Sus scrofa domestica). Various levels of psychosocial stress were induced by mixing groups of unfamiliar pigs with different aggressiveness. We selected two experimental groups for comparison, each comprising eight animals, which differed significantly in aggressive behaviour and plasma cortisol levels. To identify differentially expressed genes, we compared the adrenal transcriptome of these two groups of pigs, using the Affymetrix GeneChip porcine Genome Array. Bioinformatic analysis revealed that psychosocial stress induced upregulation of transcripts enriched for functions associated with cholesterol accumulation and downregulation of transcripts enriched for functions associated with cell growth and death. These responses are similar to those induced by ACTH stimulation. Nevertheless, the majority of the differentially expressed genes were so far not described as ACTH responsive. Some, such as $G A L$ and $G A L P$, may have responded to sympathoadrenal stimulation. Several of the differentially expressed transcripts, such as $A G T$, are associated with processes modulating steroidogenic response of adrenocortical cells to $\mathrm{ACTH}$. One of the most significant findings was upregulation of $L O C 100039095$, comprising a precursor of the microRNA miR-202, pointing to a previously unrecognised layer of regulation of adrenal steroidogenesis by microRNA. Our study, performed under entirely physiological conditions, complements previous studies focusing either on a single adrenal tissue and/or on a single stimulus, and contributes to understanding of the fine-tuning of adrenal stress response.
\end{abstract}

Journal of Molecular Endocrinology (2011) 46, 165-174

\section{Introduction}

The ability to adapt to challenges is essential for survival. The stress response is one of the most important mechanisms facilitating adaptation. Its malfunction has negative effects on well-being, health status, and in livestock animals on performance (reviewed by Moberg (2000) and Chrousos (2009)). Knowledge of the molecular genetic background of the stress response is fundamental for the identification of the sources of individual variation in adaptation potential and will provide a foundation for the prevention of maladaptive responses.

The adrenal gland plays a pivotal role in the stress response, because it secretes the main stress hormones, glucocorticoids (cortisol in the pig) from the cortex and catecholamines (adrenaline and to a lesser extent noradrenaline) from the medulla respectively. Secretion of glucocorticoids and catecholamines from the adrenal gland is principally governed by the hypothalamus-pituitary axis via ACTH and by the sympathetic nervous system via the splanchnic nerves respectively. However, the adrenal response to these stimuli is modulated by complex intrinsic regulatory circuits including interactions between cortical and medullary chromaffin cells, paracrine action of neuropeptides, innervation and blood flow (reviewed in Vinson et al. (1994), Ehrhart-Bornstein et al. (1998), Delarue et al. (2001) and Kvetnansky et al. (2009)). The action of the modulatory factors may vary depending on the character of the stressor and thus may serve the synchronisation of the response of the two main stress 
systems within the adrenal gland (Ehrhart-Bornstein et al. 1998).

The current knowledge about the intra-adrenal regulatory circuits comes mainly from morphological and functional studies. Only recently, application of microarray technology has begun to unravel the underlying complex gene networks. So far, the majority of the transcriptome studies have focused on the adrenal response to ACTH treatment in vitro (Schimmer et al. 2006, Xing et al. 2010), but also in vivo (Hazard et al. 2008, Bureau et al. 2009).

In this study, we have used microarray analysis to investigate the adrenal response to stress under physiological settings in the pig (Sus scrofa domestica). As a model stressor, we used mixing of unfamiliar pigs with different aggressiveness. Mixing of unfamiliar individuals, which commonly occurs in pig husbandry, disturbs social dominance order and consequently induces aggressive behaviour (Meese \& Ewbank 1973). Aggression is a powerful psychosocial stressor, which strongly activates both the sympathoadrenomedullary system and catecholamine release, and the hypothalamic-pituitary-adrenocortical (HPA) axis and cortisol secretion (Fernandez et al. 1994, Otten et al. 1999, D'Eath et al. 2010). We compared the adrenal transcriptome of two groups of animals differing significantly in their aggressiveness and in the amount of aggressive interactions experienced, as well as in the resulting adrenal stress response. In general, we observed transcriptome changes similar to those induced by ACTH treatment. However, we identified differential expression of several genes that may play a key role in the intra-adrenal regulatory circuits, perhaps responding specifically to psychosocial stress.

\section{Materials and methods}

\section{Animal experiment}

The animal experiment was described in detail by D'Eath et al. (2010). Briefly, aggressive temperament (aggressiveness) was measured by counting skin lesions (lesion scoring) immediately before and $24 \mathrm{~h}$ after mixing pigs into new groups at $\sim 10-11$ weeks of age. The increase in number of skin lesions (particularly at the front of the body) has been shown by Turner et al. (2006) to be positively associated with the duration of involvement in reciprocal fighting behaviour. Skin lesions at mixing are also more numerous in groups containing more aggressive individuals (D'Eath 2002). Pigs in each mixed group were ordered by the change in total skin lesions: half of the pigs in each group (those with the most lesions) were designated as high aggressiveness and the remaining half as low aggressiveness. In four slaughter batches, peripubertal pigs
( $\sim 190$ days old) were assigned to one of four mixing treatments based on their aggressiveness (number of animals per treatment available for this study: high with high $n=63$, high with low $n=61$, low with low $n=65$ and unmixed $n=64)$. Pigs were mixed into their treatment groups, as they were loaded onto a vehicle for transport to the abattoir. Skin lesions were counted before mixing and after slaughter on the carcass, dividing the body into front (head, neck, shoulders and front legs), middle (flanks and back) and rear (rump, hind legs and tail) sections. The difference in lesion number was again taken as the lesion score. The mixing treatment had significant effect on aggressive behaviour as reported by D'Eath et al. (2010). The animal experiment received approval from the Scottish Agricultural College Animal Experiments Committee.

\section{Measurement of physiological stress parameters}

Pigs were stunned by means of $\mathrm{CO}_{2}$ gas and at exsanguination; a $50 \mathrm{ml}$ sample of trunk blood was collected from each pig in a plastic tube containing $1 \mathrm{ml}$ of $0.5 \mathrm{M}$ EDTA and was stored on ice until plasma preparation, after which they were stored at $-80^{\circ} \mathrm{C}$. All blood samples were collected at morning between 0600 and $0800 \mathrm{~h}$, at the peak of the circadian rhythm of cortisol secretion in the pig (Désautés et al. 1999).

Cortisol levels were measured with the automated analyser Centaur (Siemens Healthcare Diagnostics S.A.S, St Denis, France) using a kit designed for human serum and that we validated for pig serum. The intra- and inter-assay coefficients of variation (\%) were 3.4 and 8.0 respectively.

Creatine kinase activity was measured with a clinical biochemistry automat (COBAS-MIRA Plus, Roche Diagnostics).

\section{Transcriptome profiling using microarrays}

Immediately after slaughter, the left adrenal gland was dissected, frozen in liquid nitrogen and stored at $-80^{\circ} \mathrm{C}$. For the microarray experiment, eight animals from each of the high-high and low-low mixing treatments respectively, which differed significantly in the level of psychosocial stress, were selected $(n=16$, for details see the 'Results' section and Table 1). Each slaughter batch was represented by four animals, one female and one castrated male per mixing treatment. All selected animals were free of the RYRl mutation associated with the porcine stress syndrome (Fujii et al. 1991; details on the genotyping procedure are given in D'Eath et al. 2010).

The selected samples were thoroughly ground using mortar and pestle under liquid nitrogen to ensure equal proportions of cortical and medullary tissues. RNA isolation was performed using TRI reagent 
Table 1 Differences in indicators of aggressive behaviour and physiological stress parameters between the two microarray experimental groups

\begin{tabular}{|c|c|c|c|}
\hline Parameter & $\begin{array}{l}\text { High-stress } \\
\text { group }^{\mathrm{a}}(n=8)\end{array}$ & $\begin{array}{l}\text { Low-stress } \\
\text { group }^{\mathrm{a}}(n=8)\end{array}$ & $P$ value ${ }^{*}$ \\
\hline \multicolumn{4}{|l|}{ Skin lesions $^{\mathrm{b}}$} \\
\hline Front & $69 \cdot 6 \pm 13 \cdot 2$ & $4 \cdot 5 \pm 2 \cdot 1$ & $<0.001$ \\
\hline Mid & $65 \cdot 8 \pm 15 \cdot 3$ & $9 \cdot 4 \pm 2 \cdot 4$ & 0.003 \\
\hline Rear & $13 \cdot 6 \pm 3.7$ & $5 \cdot 4 \pm 1 \cdot 7$ & 0.062 \\
\hline Total & $149 \cdot 0 \pm 27 \cdot 7$ & $19 \cdot 3 \pm 4 \cdot 0$ & $<0.001$ \\
\hline Creatine kinase (U/I) & $7547 \pm 1359$ & $2777 \pm 345$ & 0.004 \\
\hline Cortisol (ng/ml) & $69 \cdot 6 \pm 4 \cdot 7$ & $50 \cdot 3 \pm 3 \cdot 9$ & 0.007 \\
\hline
\end{tabular}

${ }^{*} P$ value of a two-sided unpaired $t$-test.

${ }^{a}$ Mean \pm S.E.M.

${ }^{b}$ Skin lesion in body sections: front (head, neck, shoulders and front legs), middle (flanks and back) and rear (rump, hind legs and tail).

(Sigma). After DNaseI treatment, the RNA was cleaned up using the RNeasy kit (Qiagen). The quantity of RNA was determined using the NanoDrop ND-1000 spectrophotometer (NanoDrop, Peqlab, Germany), and the integrity was checked by running $1 \mu \mathrm{g}$ RNA on $1 \%$ agarose gel.

Preparation of antisense biotinylated RNA targets from $500 \mathrm{ng}$ total RNA, hybridisation and scanning on a GeneChip scanner 3000 were performed according to Affymetrix protocols. The quality of hybridisation was assessed in all samples following the manufacturer's recommendations. Data were analysed with Affymetrix GCOS 1.1.1 software using global scaling to a target signal of 500. Data were then imported into Affymetrix Expression Console software for subsequent analysis. The data were first processed with MAS5.0 to generate cell intensity files and filtered (present or absent). Quantitative expression levels of the present transcripts were then estimated using Probe Logarithmic Intensity ERror (PLIER). The microarray data related to all samples were deposited in the Gene Expression Omnibus public repository (GEO accession number: GSE25138).

\section{Real-time quantitative PCR}

First strand cDNA was synthesised using SuperScript III MMLV reverse transcriptase (Invitrogen) in a reaction containing $2 \mu \mathrm{g}$ RNA, $500 \mathrm{ng}$ oligo $(\mathrm{dT})_{13} \mathrm{VN}$ primer and $500 \mathrm{ng}$ random hexamer primers (Promega), according to the manufacturer's protocol. Real-time quantitative PCR (qPCR) was performed on a LightCycler 480 System using the LightCycler 480 SYBR Green I Master (all Roche Applied Science). Primer and amplicon information is given in Supplementary Table 1, see section on supplementary data given at the end of this article. The temperature profiles consisted of an initial denaturation step at $95^{\circ} \mathrm{C}$ for $10 \mathrm{~min}$ and 45 cycles consisting of denaturation at $95^{\circ} \mathrm{C}$ for $10 \mathrm{~s}$, annealing at $60{ }^{\circ} \mathrm{C}$ for $15 \mathrm{~s}\left(55^{\circ} \mathrm{C}\right.$ for $\left.R P L 32\right)$ and extension/fluorescence acquisition at $72^{\circ} \mathrm{C}$ for $25 \mathrm{~s}$. Melting curve analysis and agarose gel electrophoresis were performed after completion of the qPCR run to confirm specificity of the amplification and absence of primer dimers. Threshold cycles were converted to copy numbers using a standard curve generated by amplifying serial dilutions of an external PCR-generated standard $\left(10^{7}-10^{2}\right.$ copies $)$. To account for variation in RNA input and efficiency of reverse transcription, the calculated copy numbers were normalised by dividing with a normalisation factor derived from the expression of the reference genes RPL32 and B2M according to the method described by Vandesompele et al. (2002).

\section{Data analysis}

Before statistical analysis, expression levels for both microarray and qPCR data were log2-transformed. In addition, microarray data were normalised using the median method implemented in JMP Genomics 4.1 Software Suite (SAS Institute, Cary, NC, USA). The effect of the psychosocial stress on gene expression was analysed using ANOVA implemented in JMP Genomics 4.1 for microarray data and in SAS 9.2 (Proc GLM; SAS Institute) for qPCR data respectively. The model included fixed effects of experimental group ('high stress' versus 'low stress', see the 'Results' section), gender, slaughter batch $(n=4)$ and microarray batch $(n=2)$. Least-square means for the two stress groups were compared using a $t$-test.

Bioinformatic analysis was performed using ingenuity pathway analysis (IPA, Ingenuity Systems, Redwood City, CA, USA). Enrichment of differentially regulated transcripts in specific functional classes and canonical pathways respectively were tested using Fisher's exact test and adjusted using the Benjamini-Hochberg correction. The Affymetrix GeneChip porcine Genome Array probe sets were annotated according to Naraballobh et al. (2010).

\section{Results}

\section{Differences in psychosocial stress and in the associated adrenal response between the experimental groups}

The samples used in this study were selected from a larger animal experiment, where different levels of aggressive behaviour and psychosocial stress were induced by mixing unfamiliar pigs with different aggressiveness (all three combinations of high with low) or leaving them in familiar groups (D'Eath et al. 2010). From each of the high-high and low-low mixing treatments respectively, eight animals were selected to 
Table 2 Comparison of microarray and quantitative PCR (qPCR) results for transcripts of interest selected for validation

\begin{tabular}{|c|c|c|c|c|c|c|}
\hline \multirow[b]{2}{*}{ Probe set ID } & \multirow[b]{2}{*}{ Gene ID } & \multirow[b]{2}{*}{ Function } & \multicolumn{2}{|c|}{ Microarray } & \multicolumn{2}{|l|}{ qPCR } \\
\hline & & & $\mathrm{FC}^{\mathrm{a}}(\mathrm{H} / \mathrm{L})$ & $P$ value & $\mathrm{FC}^{\mathrm{a}}(\mathrm{H} / \mathrm{L})$ & $P$ value \\
\hline Ssc.914.1.S1_at & LOC100039095 & Unknown & $2 \cdot 6$ & 0.001 & $2 \cdot 2$ & 0.010 \\
\hline Ssc.4875.1.S1__at & $G A L P$ & Neuropeptide & $1 \cdot 7$ & 0.043 & $2 \cdot 7$ & 0.092 \\
\hline Ssc.713.1.S1_at & $G A L$ & Neuropeptide & $1 \cdot 6$ & 0.038 & $1 \cdot 6$ & 0.051 \\
\hline Ssc.18298.1.Ā1_a_at & RGS2 & Signal transduction & $1 \cdot 6$ & 0.007 & $1 \cdot 6$ & $0 \cdot 104$ \\
\hline Ssc.16088.1.S1_at & $H M G C R$ & Cholesterol biosynthesis & $1 \cdot 4$ & 0.035 & $1 \cdot 4$ & 0.099 \\
\hline Ssc.15388.2.S1_at & $\mathrm{TH}$ & Catecholamine biosynthesis & $1 \cdot 3$ & 0.028 & $1 \cdot 5$ & 0.026 \\
\hline Ssc.4804.1.S1_at & $A G T$ & Hormone & $-1 \cdot 5$ & 0.024 & $-1 \cdot 5$ & 0.032 \\
\hline Ssc.15741.1.S1_s_at & CYP2E1 & Steroid metabolism & $-1 \cdot 4$ & 0.034 & $-2 \cdot 0$ & 0.033 \\
\hline Ssc.15952.1.S1_at & $N R 3 C 1$ & Transcription factor & $-1 \cdot 3$ & 0.004 & $-1 \cdot 3$ & 0.006 \\
\hline Ssc.26267.1.S1_at & CRY2 & Circadian rhythm & $-1 \cdot 3$ & 0.000 & $-1 \cdot 5$ & 0.031 \\
\hline Ssc.24696.1.S1_at & IRS2 & Signal transduction & $-1 \cdot 3$ & 0.007 & $-1 \cdot 5$ & 0.086 \\
\hline Ssc.30607.1.A1_at & CALM1 & Signal transduction & $-1 \cdot 2$ & 0.003 & $-1 \cdot 2$ & 0.010 \\
\hline Ssc.16976.1.S1_at & SREBF2 & Transcription factor & $1 \cdot 1$ & $0 \cdot 100$ & $1 \cdot 1$ & 0.638 \\
\hline
\end{tabular}

${ }^{\mathrm{a}}$ Fold change in expression levels between the high- and low-stress groups respectively.

create two microarray experimental groups, designated 'high stress' and 'low stress'. The two experimental groups differed significantly in the amount of aggressive interactions induced by the treatment (i.e. in the level of psychosocial stress) as indicated by their skin lesions, primarily at the front of the body, which are known to be acquired during fighting (Table 1), and by their plasma creatine kinase level (a parameter reflecting damage of muscle fibres due to strenuous physical activity, Table 1), as well as in the resulting adrenal response as indicated by significantly different plasma cortisol levels (Table 1). Thus, the two experimental groups provided suitable material to study the adrenal response to psychosocial stress.

\section{Microarray results and validation using qPCR}

Out of the 23937 probe sets on the Affymetrix GeneChip porcine Genome Array, 13337 probe sets $(\sim 56 \%)$ were found to be expressed and were evaluated for differential expression. A total of 816 probe sets showed differential expression between the two experimental groups (469 up- and 347 downregulated; Supplementary Table 2, see section on supplementary data given at the end of this article) at the nominal significance level $P \leq 0 \cdot 05$. The magnitude of the differential expression ranged from 2.6-fold (upregulated in the high-stress group) to $-1 \cdot 9$-fold (downregulated in the high-stress group). Overall, however, the differences in the expression were slight; only 23 probe sets showed higher than \pm 1.5 -fold differential expression.

To validate the microarray experiment, we performed qPCR analysis for 13 transcripts that represent various functional classes and show a wide range of fold differences, including one transcript (SREBF2) showing only non-significant differences $(P \leq 0 \cdot 10$, Table 2$)$.
Comparison of the results revealed a high correspondence between both methods in terms of direction and magnitude of the differential expression (Table 2). For eight of the twelve regulated transcripts, statistically significant differential expression was confirmed $(P \leq 0 \cdot 05)$, and for the remaining four transcripts, the differences approached significance $(P \leq 0 \cdot 10)$. For SREBF2, qPCR analysis confirmed the absence of statistically significant difference. Taken together, the qPCR analysis proved the validity of the microarray data.

\section{Results of the bioinformatic analysis}

To gain insight into processes and pathways in the adrenal gland affected by psychosocial stress, we performed IPA. A total of 768 annotated probe sets, representing 713 unique transcripts (418 up- and 294 downregulated), were used for IPA. We analysed upand downregulated transcripts separately, since, similar

Table 3 Functional categorisation of transcripts upregulated in the high-stress group, obtained using ingenuity pathway analysis

\begin{tabular}{|c|c|c|}
\hline $\begin{array}{l}\text { Molecular and } \\
\text { cellular function }\end{array}$ & $\begin{array}{l}-\log 10 \\
(P \text { value })^{\star}\end{array}$ & $\begin{array}{l}\text { Number of } \\
\text { transcripts }\end{array}$ \\
\hline Lipid metabolism & 5.08 & 44 \\
\hline Small molecule biochemistry & $5 \cdot 08$ & 78 \\
\hline Vitamin and mineral metabolism & $5 \cdot 08$ & 17 \\
\hline Energy production & $1 \cdot 82$ & 10 \\
\hline Molecular transport & $1 \cdot 82$ & 27 \\
\hline Nucleic acid metabolism & $1 \cdot 82$ & 24 \\
\hline RNA post-transcriptional modification & $1 \cdot 33$ & 13 \\
\hline Carbohydrate metabolism & $1 \cdot 30$ & 30 \\
\hline Cellular assembly and organisation & $1 \cdot 16$ & 31 \\
\hline Cell morphology & $1 \cdot 14$ & 25 \\
\hline
\end{tabular}

${ }^{*} P$ value after the Benjamini-Hochberg adjustment, significance threshold $=1 \cdot 30$. 
Table 4 The ten most enriched ingenuity pathway analysis canonical pathways among the transcripts upregulated in the high-stress group

\begin{tabular}{|c|c|c|c|}
\hline Pathway & $\begin{array}{l}-\log 10 \\
(P \text { value })^{\star}\end{array}$ & Ratio $^{a}$ & $\begin{array}{l}\text { Number of } \\
\text { transcripts }\end{array}$ \\
\hline Biosynthesis of steroids & $4 \cdot 25$ & $6 \cdot 25$ & 8 \\
\hline Purine metabolism & 1.93 & $4 \cdot 10$ & 18 \\
\hline$N$-glycan biosynthesis & 1.93 & $7 \cdot 53$ & 7 \\
\hline $\begin{array}{l}\text { Protein ubiquitination } \\
\text { pathway }\end{array}$ & 0.90 & $5 \cdot 47$ & 11 \\
\hline $\begin{array}{l}\text { NRF2-mediated oxidative } \\
\text { stress response }\end{array}$ & 0.80 & $5 \cdot 46$ & 10 \\
\hline $\begin{array}{l}\text { Role of CHK proteins in cell } \\
\text { cycle checkpoint control }\end{array}$ & $0 \cdot 70$ & $11 \cdot 40$ & 4 \\
\hline $\begin{array}{l}\text { LPS/IL1-mediated inhibition } \\
\text { of RXR function }\end{array}$ & 0.55 & $4 \cdot 65$ & 10 \\
\hline $\begin{array}{l}\text { Aminoacyl-tRNA } \\
\text { biosynthesis }\end{array}$ & 0.52 & $4 \cdot 82$ & 4 \\
\hline One carbon pool by folate & 0.48 & $7 \cdot 69$ & 3 \\
\hline Amino sugars metabolism & 0.36 & $4 \cdot 10$ & 5 \\
\hline
\end{tabular}

${ }^{\star} P$ value after the Benjamini-Hochberg adjustment, significance threshold $=1 \cdot 30$.

${ }^{a}$ Number of genes in a given pathway that meet cut-off criteria, divided by total number of genes that make up that pathway in percentage.

to the study of Schimmer et al. (2006), using this approach, we obtained more clear-cut results.

The transcripts involved in metabolism, e.g. lipid metabolism, dominate among those upregulated in response to psychosocial stress (see Table 3 for the overview of significantly enriched functions and Supplementary Table 3 for a complete list of genes assigned to individual functional classes). The most common transcripts in this functional class are those encoding enzymes involved in cholesterol metabolism, primarily in biosynthesis (13 out of 23 in this pathway, e.g. HMGCR encoding the rate-limiting enzyme for cholesterol biosynthesis) but also in esterification/storage (e.g. SOAT1). The precursor of cholesterol biosynthesis, acetyl-CoA, is derived from glucose or fatty acid metabolism. Enrichment of transcripts related to carbohydrate metabolism and energy production (e.g. $H K 2$ that increases the rate of glycolysis) may thus indicate stimulation of production of acetyl-CoA to maintain sufficient substrate delivery. Another abundant functional group represents transcripts related to molecular transport, including $L D L R$ and SCARB1 involved in cholesterol uptake. $L D L R$ showed higher upregulation compared with SCARB1 (1.3 vs 1.1) indicating that, similar to humans, the LDLR-mediated endocytic uptake of cholesterol is more important than the selective pathway mediated by SCARB1 (Kraemer 2007). A constant supply of cholesterol, either via de novo synthesis or uptake, is required within adrenal cells to serve as a precursor for the conversion to steroid hormones (Kraemer 2007). Our results indicate that both supply routes play an important role.
Delivery of free cholesterol to the inner mitochondrial membrane is the first and rate-limiting step in steroid hormone biosynthesis. This is facilitated by a macromolecular complex whose essential component is the steroidogenic acute regulatory protein (STAR; Sewer et al. 2007). However, neither the STAR gene nor genes encoding enzymes of the steroid hormone synthesis pathway (present on the microarray: CYP11A1, CYP17A1 and HSD3B2) showed significant differential expression.

In Table 4, ten canonical pathways, showing the highest enrichment among the upregulated transcripts, are shown (genes assigned to individual canonical pathways are listed in Supplementary Table 4, see section on supplementary data given at the end of this article). For three of these, the enrichment reached significance level after the Benjamini-Hochberg correction. The most pronounced enrichment showed the biosynthesis of steroids pathway, which participates in cholesterol biosynthesis. Upregulation of the purine metabolism pathway, linked with ATP synthesis, is in line with the stimulation of energy production but may also indicate stimulation of cAMP synthesis, important for ACTH signal transduction (Sewer et al. 2007). The importance of the third enriched canonical pathway, $\mathrm{N}$-glycan biosynthesis, is not obvious in the given context.

The transcripts downregulated in response to psychosocial stress are enriched in functional categories related to cell death, growth and proliferation (see Table 5 for the overview of significantly enriched functions and Supplementary Table 5 for a complete list of genes assigned to individual functional classes). It appears that the effect on cell death and cell growth is bidirectional, since both positive and negative regulators of cell survival (e.g. SMAD1 and DEDD respectively) and growth (e.g. IGFR1 and SMARCA2 respectively) were downregulated. Another abundant functional class represents transcripts related to gene expression,

Table 5 Functional categorisation of transcripts downregulated in the high-stress group, obtained using ingenuity pathway analysis

\begin{tabular}{|c|c|c|}
\hline $\begin{array}{l}\text { Molecular and } \\
\text { cellular function }\end{array}$ & $\begin{array}{l}-\log 10 \\
(P \text { value })^{\star}\end{array}$ & $\begin{array}{l}\text { Number of } \\
\text { transcripts }\end{array}$ \\
\hline Gene expression & $2 \cdot 16$ & 59 \\
\hline Cell death & $2 \cdot 03$ & 71 \\
\hline Cellular development & $1 \cdot 56$ & 34 \\
\hline Cellular growth and proliferation & $1 \cdot 46$ & 71 \\
\hline Cell cycle & $1 \cdot 46$ & 39 \\
\hline Lipid metabolism & $1 \cdot 41$ & 14 \\
\hline Small molecule biochemistry & $1 \cdot 41$ & 23 \\
\hline Cellular assembly and organisation & $1 \cdot 13$ & 22 \\
\hline Carbohydrate metabolism & $1 \cdot 07$ & 15 \\
\hline Cellular compromise & $1 \cdot 07$ & 13 \\
\hline
\end{tabular}

${ }^{\star} P$ value after the Benjamini-Hochberg adjustment, significance threshold $=1 \cdot 30$ 
Table 6 The ten most enriched ingenuity pathway analysis canonical pathways among the transcripts downregulated in the high-stress group

\begin{tabular}{|c|c|c|c|}
\hline Pathway & $\begin{array}{l}-\log 10 \\
(P \text { value })^{\star}\end{array}$ & Ratio $^{\mathrm{a}}$ & $\begin{array}{l}\text { Number of } \\
\text { transcripts }\end{array}$ \\
\hline Hepatic fibrosis/hepatic stellate cell activation & $1 \cdot 07$ & $5 \cdot 97$ & 8 \\
\hline Cell cycle: $\mathrm{G}_{2} / \mathrm{M}$ DNA damage checkpoint regulation & 0.70 & $9 \cdot 30$ & 4 \\
\hline IGF1 signalling & 0.22 & $5 \cdot 00$ & 5 \\
\hline PXR/RXR activation & 0.13 & $4 \cdot 40$ & 4 \\
\hline Oestrogen receptor signalling & 0.13 & $4 \cdot 20$ & 5 \\
\hline Glucocorticoid receptor signalling & $0 \cdot 12$ & $2 \cdot 86$ & 8 \\
\hline DNA methylation and transcriptional repression signalling & 0.12 & $8 \cdot 70$ & 2 \\
\hline Fatty acid metabolism & 0.12 & $2 \cdot 60$ & 5 \\
\hline$\beta$-Alanine metabolism & $0 \cdot 12$ & 3.06 & 3 \\
\hline Pantothenate and CoA biosynthesis & 0.12 & $3 \cdot 12$ & 2 \\
\hline
\end{tabular}

$P$ value after the Benjamini-Hochberg adjustment, significance threshold $=1 \cdot 30$.

aNumber of genes in a given pathway that meet cut-off criteria, divided by total number of genes that make up that pathway in percentage.

including those involved in steroid hormone signalling (e.g. NR3C1 encoding glucocorticoid receptor).

As found for upregulated transcripts, genes linked to lipid metabolism were also found among downregulated transcripts. Downregulation of $A B C A 1$, which is involved in cholesterol efflux, provides additional evidence of the coordinated regulation of several processes towards accumulation of cholesterol.

In Table 6, ten canonical pathways are shown with the highest enrichment among the downregulated transcripts (genes assigned to individual canonical pathways are listed in Supplementary Table 6, see section on supplementary data given at the end of this article). Considering the enriched functional categories, several of the identified canonical pathways appear meaningful, e.g. the insulin-like growth factor 1 (IGF1) or glucocorticoid receptor signalling pathways related to cell proliferation and gene expression respectively; however, none reached significance after the Benjamini -Hochberg correction for multiple testing.

We compared our list of genes differentially expressed following psychosocial stress with lists of genes reported as ACTH responsive in vitro (Schimmer et al. 2006) and in vivo (Hazard et al. 2008, Bureau et al. 2009). Only about $10 \%$ genes were found to be overlapping (Supplementary Table 7, see section on supplementary data given at the end of this article). Those are mainly associated with cholesterol accumulation, regulation of gene expression and cell proliferation and cell death.

\section{Discussion}

This is the first study to report on global adrenal transcriptome response to psychosocial stress. Expectedly, given the known effect of psychosocial stress on HPA axis activity and the higher plasma cortisol levels in the high-stress group, the observed transcriptome responses in many aspects resemble those induced by ACTH in vivo and in vitro. One common observation is that both the psychosocial stress and the ACTH treatment induce expression changes of relatively low magnitude (Schimmer et al. 2006, Hazard et al. 2008, Bureau et al. 2009, Xing et al. 2010). These small changes were most likely further obscured by interindividual variability in stress response, which is usually very high (Mormede et al. 2002). Moreover, because we analysed transcriptome of the whole adrenal gland, the overall expression changes were potentially under- or overestimated for genes that show anti-parallel or parallel changes respectively in different adrenal compartments.

Genes associated with regulation of gene expression were almost exclusively downregulated. One gene that stands out among these is NR3C1 encoding the glucocorticoid receptor, which provides negative feedback regulation of the HPA axis activity mainly at the central (Steckler 2001) but also at the adrencortical level (Gummow et al. 2006). Downregulation of NR3C1 was also described in response to ACTH stimulation in vitro (Schimmer et al. 2006).

In contrast, upregulated genes were enriched, i.e. for those associated with RNA post-transcriptional modification. This finding, together with several other lines of evidence discussed below, points to an important role of post-transcriptional mechanisms in adrenal stress response, offering a potential explanation for the relatively weak transcriptional response. For instance, the highest magnitude of differential expression showed LOC100039095 ( 2·6-fold upregulated in the high-stress group), comprising a precursor of the microRNA miR-202. MicroRNAs are involved in posttranscriptional regulation of gene expression, mainly by repression of translation but also by promoting mRNA decay (reviewed by Krol et al. (2010)). Predicted targets 
of miR-202 include CREM (John et al. 2004), a transcription factor involved in the regulation of STAR expression and in the transduction of ACTH signalling (Sewer et al. 2007). The predominant expression of miR-202 in steroidogenic tissues such as ovary and testis (Ahn et al. 2010, Luo et al. 2010) provides additional evidence that miR-202 might be involved in the regulation of steroidogenesis.

Similar to findings reported for the ACTH response, we observed consistent upregulation of transcripts involved in cholesterol biosynthesis (Schimmer et al. 2006, Bureau et al. 2009) and uptake (Schimmer et al. 2006, Hazard et al. 2008). This response was likely, at least partly, mediated by the activation of SREBF2, a transcription factor playing a key role in the regulation of cholesterol accumulation (reviewed in Sato (2010)). The activation mechanism was obviously post-transcriptional, because we found no significant differences in SREBF2 expression. Indeed, proteolytic processing of SREBF2 in the golgi complex is required for its activation (reviewed in Sato (2010)). SREBFs are synthesised as precursor proteins in the endoplasmic reticulum (ER), where they form a complex with another protein, SCAP. The SCAP molecule contains a sterol sensory domain. In the presence of high cellular sterol concentrations, SCAP binds to another ER membrane protein, INSIG, and confines SREBP to the ER. With low cellular concentrations, SCAP escorts SREBP to activation in the golgi complex (reviewed in Sato (2010)). Hence, increased cortisol secretion in the high-stress group most likely depleted cholesterol stores in the adrenocortical cells, leading to activation of SREBF2.

Whereas upregulation of cholesterol accumulation appears to be a robust response to ACTH, transcriptional regulation of steroid hormone biosynthesis depends upon duration of the ACTH stimulus. Upregulation of the steroid hormone biosynthesis pathway occurs after long-term (Schimmer et al. 2006), but not after short-term, ACTH stimulation (Hazard et al. 2008, Bureau et al. 2009). The absence of differential expression of the steroid hormone biosynthesis pathway in our experiment is consistent with the fact that the stress exposure was transient rather than persistent.

Synchronisation between ACTH secretion and the adrenal clockwork is required to achieve appropriate response in the regulation of circadian rhythm of cortisol secretion (Oster et al. 2006). However, little is known about the regulation of the clock genes in response to acute ACTH stimulation. We found downregulation of $C R Y 2$, encoding cryptochrome 2, in the high-stress group. Cryptochrome 2 is a component of the negative limb of the circadian feedback loop. The pattern of circadian expression of cryptochromes is nearly completely opposite to the circadian rhythm of cortisol secretion (Lemos et al. 2006). It could therefore be speculated that downregulation of $C R Y 2$ in the high-stress group may be an indication of the synchronisation of acute ACTH response with the adrenal clockwork action.

Besides its principal role in the regulation of steroid hormone synthesis and secretion, ACTH is also involved in the control of adrenal growth and functional architecture (Coll et al. 2004, Karpac et al. 2005). Accordingly, ACTH affects expression of transcripts associated with cell structure, adhesion and proliferation (Schimmer et al. 2006, Hazard et al. 2008). Adrenocortical cells undergo marked morphological changes in response to ACTH in vitro, implying reorganisation of their cytoskeleton (Hall \& Almahbobi 1997). Cytoskeleton is involved in cholesterol transport and facilitates steroidogenesis by promoting interorganelle trafficking of intermediary metabolites (Sewer \& Li 2008). The enrichment of the functional category 'cellular assembly and organisation' approached significance both among up- and downregulated transcripts. This finding indicates that remodelling of the cytoskeleton may occur also in response to ACTH in vivo. Similar to transcriptional regulation of steroid hormone biosynthesis, the effect of ACTH on proliferation of adrenocortical cells also seems to be dependent upon the duration of the stimulus. Arola et al. (1993) have shown that in primary adrenocortical cell culture, ACTH has a biphasic effect with initial growth inhibition followed by later growth stimulation. Thus, the simultaneous downregulation of growth-stimulating and -inhibiting factors in the highstress group may reflect the biphasic effect of ACTH on adrenocortical cell growth. The balance was perhaps shifted towards growth inhibition, as indicated by downregulation of angiotensinogen (AGT), the precursor of angiotensin II, an important factor in the positive regulation of adrenal growth (Huckle \& Earp 1994, Vinson 2003). The systemic renin-angiotensin system is the principal activator of aldosterone production in the zona glomerulosa (Sewer et al. 2007). However, in addition to its role in aldosterone secretion, the zona glomerulosa is considered to be the site of proliferation, recruitment and differentiation of adrenocortical cell under the control of the locally produced angiotensin II (Vinson 2003). In vascular smooth muscle, angiotensin II stimulates cell growth through activation of $I G F 1 R$ transcription. This effect is mediated via calcium-dependent activation of protein tyrosine kinase activity (Du et al. 1999). We found downregulation of IGFIR and CALM1, the latter involved in calcium signalling, which indicates that the IGF1 signalling pathway may be a mediator of the effects of angiotensin II on the proliferation of adrenocortical cells.

Given the potent vasoconstrictory effect of angiotensin II, downregulation of AGT could serve an additional 
function, namely increasing the adrenal blood flow (Ehrhart-Bornstein et al. 1998). The observed upregulation of RGS2 could further augment this effect, because RGS2 promotes vascular relaxation by attenuating angiotensin II signalling (Goncalves et al. 2008). The rate of blood flow modulates glucocorticoid secretion by influencing presentation of ACTH to the adrenal gland (reviewed in Ehrhart-Bornstein et al. (1998)). $A G T$ and $R G S 2$ were most likely regulated in response to ACTH, which is well known to stimulate increases in adrenal blood flow. Furthermore, expression of both $A G T$ and RGS2 was previously reported to be ACTH responsive (Schimmer et al. 2006, Hazard et al. 2008).

The steroidogenic response of adrenocortical cells to ACTH is additionally modulated in a paracrine way by neurotransmitters and neuropeptides released from medullary chromaffin cells (reviewed in EhrhartBornstein et al. (1998) and Delarue et al. (2001)). This was demonstrated for example by the finding that deletion of the tyrosine hydroxylase $(T H)$ gene, encoding the rate-limiting enzyme of catecholamine synthesis, leads to a marked decrease in plasma glucocorticoid level (Bornstein et al. 2000). Chromaffin cells express a wide range of neuropeptides (reviewed in Ehrhart-Bornstein et al. (1998)). We found upregulation of two members of the galanin neuropeptide family, galanin $(G A L)$ and galanin-like peptide $(G A L P)$. Porcine adrenal medulla contains high concentration of $G A L$, which upon stimulation of the splanchnic nerve is released in large amounts (Holst et al. 1991). Moreover, depolarisation of chromaffin cells upregulates expression of GAL (Rokaeus et al. 1990). Perfusion of isolated porcine adrenal glands with $G A L$ increases cortisol secretion (Holst et al. 1991). In rodents, two routes of the paracrine stimulation of glucocorticoid secretion by $G A L$ were described: through direct activation of adrenocortical GAL receptors and through stimulation of adrenomedullary release of catecholamines, which in turn activate $\beta$ adrenoceptors located on adrenocortical cells (Andreis et al. 2007). With regards to $G A L P$, it is known to affect the function of the HPA axis at the central level (reviewed in Suzuki et al. (2010)); however, knowledge about its expression and function at the adrenal level is currently lacking. The magnitude of differential expression of both $G A L$ and GALP was among the highest in our experiment. Furthermore, we found upregulation of $\mathrm{TH}$ in the high-stress group. Taken together, our results indicate that the adrenomedullary and adrenocortical responses to psychosocial stress might have been synchronised, whereby the GALP family might have played an important role.

The large inter-individual variation in stress responsiveness has to some extent genetic background. Differences in cortisol secretion between pig breeds were demonstrated and utilised for quantitative trait loci mapping (Désautés et al. 1999, 2002). This contributes a list of functional candidate genes. For one differentially expressed gene from our list, NR3C1, we already found a significant association with cortisol secretion and adrenal size (Murani et al. 2010). Another interesting candidate on our list is CYP2E1, which is involved in steroid metabolism (Ball et al. 1990). Polymorphisms of porcine CYP2E1 show an effect on skatole level, a compound causing boar taint (Moe et al. 2009). The question of whether CYP2E1 polymorphisms show pleiotropic effects also on cortisol levels merits further investigation.

In summary, to gain insight into the adrenal stress response, we analysed transcriptome changes associated with psychosocial stress, activating both adrenal cortex and medulla.

Several processes (e.g. cholesterol accumulation and cell proliferation) and key molecules/pathways (e.g. $A G T)$ responded in a fashion similar to earlier reports of ACTH stimulation. Nevertheless, the majority of the regulated genes were so far not described as ACTH responsive. Some, such as GAL and GALP, may have responded to splanchnic nerves, i.e. sympathoadrenal stimulation. Several of the differentially expressed transcripts are associated with processes modulating steroidogenic response of adrenocortical cells to ACTH. One of the most significant findings was upregulation of LOC100039095, pointing to a previously unrecognised layer of regulation of adrenal steroidogenesis by microRNA. Our study, performed under entirely physiological conditions, complements previous studies focusing either on single adrenal tissue and/or on single stimulus, and contributes to understanding of the fine-tuning of adrenal stress response.

\section{Supplementary data}

This is linked to the online version of the paper at http://dx.doi.org/ 10.1530/JME-10-0147.

\section{Declaration of interest}

The authors declare that there is no conflict of interest that could be perceived as prejudicing the impartiality of the research reported.

\section{Funding}

This work was part-funded by the 6th Research Framework Programme of the European Union European Commission as part of the SABRE (Cutting-Edge Genomics for Sustainable Animal Breeding) Integrated Project. FBN, PIC and INRA provided their own matched funding. SAC matched funding was provided by the Rural and Environment Research and Analysis Directorate of the Scottish Government. 


\section{Acknowledgements}

The authors thank Angela Garve, Annette Jugert, Kerstin Jahnke and Marlies Fuchs for their excellent technical help. We are also grateful to Sarah H Ison for expertly performing the lesion scoring, and to Peter Andresen for allowing his pigs and farm to be used for the animal experiment.

\section{References}

Ahn HW, Morin RD, Zhao H, Harris RA, Coarfa C, Chen ZJ, Milosavljevic A, Marra MA \& Rajkovic A 2010 MicroRNA transcriptome in the newborn mouse ovaries determined by massive parallel sequencing. Molecular Human Reproduction $\mathbf{1 6}$ 463-471. (doi:10.1093/molehr/gaq017)

Andreis PG, Tortorella C, Ziolkowska A, Spinazzi R, Malendowicz LK, Neri G \& Nussdorfer GG 2007 Evidence for a paracrine role of endogenous adrenomedullary galanin in the regulation of glucocorticoid secretion in the rat adrenal gland. International Journal of Molecular Medicine 19 511-515.

Arola J, Heikkila P \& Kahri AI 1993 Biphasic effect of ACTH on growth of rat adrenocortical-cells in primary culture. Cell and Tissue Research 271 169-176. (doi:10.1007/BF00297555)

Ball SE, Forrester LM, Wolf CR \& Back DJ 1990 Differences in the cytochrome-P-450 isoenzymes involved in the 2-hydroxylation of estradiol and 17-alpha-ethinylestradiol - relative activities of rat and human liver-enzymes. Biochemical Journal 267 221-226.

Bornstein SR, Tian H, Haidan A, Bottner A, Hiroi N, Eisenhofer G, Mccann SM, Chrousos GP \& Roffler-Tarlov S 2000 Deletion of tyrosine hydroxylase gene reveals functional interdependence of adrenocortical and chromaffin cell system in vivo. PNAS $\mathbf{9 7}$ 14742-14747. (doi:10.1073/pnas.97.26.14742)

Bureau C, Hennequet-Antier C, Couty M \& Guemene D 2009 Gene array analysis of adrenal glands in broiler chickens following ACTH treatment. BMC Genomics 10 430. (doi:10.1186/1471-2164-10-430)

Chrousos GP 2009 Stress and disorders of the stress system. Nature Reviews. Endocrinology 5 374-381. (doi:10.1038/nrendo.2009.106)

Coll AP, Challis BG, Yeo GSH, Snell K, Piper SJ, Halsall D, Thresher RR \& O'Rahilly S 2004 The effects of proopiomelanocortin deficiency on murine adrenal development and responsiveness to adrenocorticotropin. Endocrinology 145 4721-4727. (doi:10.1210/ en.2004-0491)

D'Eath RB 2002 Individual aggressiveness measured in a residentintruder test predicts the persistence of aggressive behaviour and weight gain of young pigs after mixing. Applied Animal Behaviour Science 77 267-283. (doi:10.1016/S0168-1591(02)00077-1)

D'Eath RB, Turner SP, Kurt E, Evans G, Tholking L, Looft H, Wimmers K, Murani E, Klont R, Foury A et al. 2010 Pigs' aggressive temperament affects pre-slaughter mixing aggression, stress and meat quality. Animal 4 604-616. (doi:10.1017/S1751731109991406)

Delarue C, Contesse V, Lenglet S, Sicard F, Perraudin V, Lefebvre H, Kodjo M, Leboulenger F, Yon L, Gallo-Payet N et al. 2001 Role of neurotransmitters and neuropeptides in the regulation of the adrenal cortex. Reviews in Endocrine and Metabolic Disorders 2 253-267. (doi:10.1023/A:1011512415497)

Désautés C, Sarrieau A, Caritez JC \& Mormede P 1999 Behavior and pituitary-adrenal function in Large White and Meishan pigs. Domestic Animal Endocrinology 16 193-205. (doi:10.1016/S07397240(99)00014-4)

Désautés C, Bidanel JP, Milan D, Iannuccelli N, Amigues Y, Bourgeois F, Caritez JC, Renard C, Chevalet C \& Mormede P 2002 Genetic linkage mapping of quantitative trait loci for behavioral and neuroendocrine stress response traits in pigs. Journal of Animal Science 80 2276-2285.

Du J, Peng T, Scheidegger KJ \& Delafontaine P 1999 Angiotensin II activation of insulin-like growth factor 1 receptor transcription is mediated by a tyrosine kinase-dependent redox-sensitive mechanism. Arteriosclerosis, Thrombosis, and Vascular Biology 19 2119-2126.

Ehrhart-Bornstein M, Hinson JP, Bornstein SR, Scherbaum WA \& Vinson GP 1998 Intraadrenal interactions in the regulation of adrenocortical steroidogenesis. Endocrine Reviews 19 101-143. (doi:10.1210/er.19.2.101)

Fernandez X, Meunier-Salaun MC \& Mormede P 1994 Agonistic behavior, plasma stress hormones, and metabolites in response to dyadic encounters in domestic pigs: interrelationships and effect of dominance status. Physiology and Behavior 56 841-847. (doi:10.1016/ 0031-9384(94)90313-1)

Fujii J, Otsu K, Zorzato F, de Leon S, Khanna VK, Weiler JE, O'Brien PJ \& MacLennan DH 1991 Identification of a mutation in porcine ryanodine receptor associated with malignant hyperthermia. Science 253 448-451. (doi:10.1126/science.1862346)

Goncalves ACD, Luft FC \& Gross V 2008 Fine tuning of blood pressure by the regulator of $\mathrm{G}$ protein signaling (RGS) 2. Journal of the American Society of Hypertension 2 403-409. (doi:10.1016/j.jash.2008.05.006)

Gummow BM, Scheys JO, Cancelli VR \& Hammer GD 2006 Reciprocal regulation of a glucocorticoid receptor-steroidogenic factor-1 transcription complex on the Dax-1 promoter by glucocorticoids and adrenocorticotropic hormone in the adrenal cortex. Molecular Endocrinology 20 2711-2723. (doi:10.1210/me.2005-0461)

Hall PF \& Almahbobi G 1997 Roles of microfilaments and intermediate filaments in adrenal steroidogenesis. Microscopy Research and Technique 36 463-479. (doi:10.1002/(SICI) 10970029(19970315) 36:6 < 463::AID-JEMT4 > 3.0.CO;2-J)

Hazard D, Liaubet L, SanCristobal M \& Mormede P 2008 Gene array and real time PCR analysis of the adrenal sensitivity to adrenocorticotropic hormone in pig. BMC Genomics 9 101. (doi:10.1186/ 1471-2164-9-101)

Holst JJ, Ehrhart-Bornstein M, Messell T, Poulsen SS \& Harling H 1991 Release of galanin from isolated perfused porcine adrenal glands: role of splanchnic nerves. American Journal of Physiology. Endocrinology and Metabolism 261 E31-E40.

Huckle WR \& Earp HS 1994 Regulation of cell proliferation and growth by angiotensin II. Progress in Growth Factor Research 5 177-194. (doi:10.1016/0955-2235(94)90004-3)

John B, Enright AJ, Aravin A, Tuschl T, Sander C \& Marks DS 2004 Human MicroRNA targets. PLoS Biology 2 1862-1879. (doi:10.1371/ journal.pbio.0020363)

Karpac J, Ostwald D, Bui S, Hunnewell P, Shankar M \& Hochgeschwender U 2005 Development, maintenance, and function of the adrenal gland in early postnatal proopiomelanocortin-null mutant mice. Endocrinology 146 2555-2562. (doi:10.1210/en.2004-1290)

Kraemer FB 2007 Adrenal cholesterol utilization. Molecular and Cellular Endocrinology 265 42-45. (doi:10.1016/j.mce.2006.12.001)

Krol J, Loedige I \& Filipowicz W 2010 The widespread regulation of microRNA biogenesis, function and decay. Nature Reviews. Genetics 11 597-610. (doi:10.1038/nrg2843)

Kvetnansky R, Sabban EL \& Palkovits M 2009 Catecholaminergic systems in stress: structural and molecular genetic approaches. Physiological Reviews 89 535-606. (doi:10.1152/physrev.00042.2006)

Lemos DR, Downs JL \& Urbanski HF 2006 Twenty-four-hour rhythmic gene expression in the rhesus macaque adrenal gland. Molecular Endocrinology 20 1164-1176. (doi:10.1210/me.2005-0361)

Luo LF, Ye LZ, Liu G, Shao GC, Zheng R, Ren ZQ, Zuo B, Xu DQ, Lei MG, Jiang SW et al. 2010 Microarray-based approach identifies differentially expressed micrornas in porcine sexually immature and mature testes. PLoS ONE 5 e11744. (doi:10.1371/journal.pone. 0011744)

Meese GB \& Ewbank R 1973 Exploratory behaviour and leadership in the domesticated pig. British Veterinary Journal 129 251-259.

Moberg GP 2000 Biological response to stress: implications for animal welfare. In The Biology of Animal Stress: Basic Principles and Implications for Animal Welfare, pp 1-21. Wallingford, UK: CABI Publishing. 
Moe M, Lien S, Aasmundstad T, Meuwissen T, Hansen M, Bendixen C \& Grindflek E 2009 Association between SNPs within candidate genes and compounds related to boar taint and reproduction. $B M C$ Genetics 10 5. (doi:10.1186/1471-2156-10-32)

Mormede P, Courvoisier H, Ramos A, Marissal-Arvy N, Ousova O, Desautes C, Duclos M, Chaouloff F \& Moisan MP 2002 Molecular genetic approaches to investigate individual variations in behavioral and neuroendocrine stress responses. Psychoneuroendocrinology 27 563-583. (doi:10.1016/S0306-4530(01)00093-2)

Murani E, Ponsuksili S, D'Eath R, Turner S, Kurt E, Evans G, Tholking L, Klont R, Foury A, Mormede P et al. 2010 Association of HPA axis-related genetic variation with stress reactivity and aggressive behaviour in pigs. BMC Genetics 11 9. (doi:10.1186/ 1471-2156-11-74)

Naraballobh W, Chomdej S, Murani E, Wimmers K \& Ponsuksili S 2010 Annotation and in silico localization of the Affymetrix GeneChip Porcine Genome Array. Archiv für Tierzucht-Archives of Animal Breeding 53 230-238.

Oster H, Damerow S, Kiessling S, Jakubcakova V, Abraham D, Tian J, Hoffmann MW \& Eichele G 2006 The circadian rhythm of glucocorticoids is regulated by a gating mechanism residing in the adrenal cortical clock. Cell Metabolism 4 163-173. (doi:10.1016/ j.cmet.2006.07.002)

Otten W, Puppe B, Kanitz E, Schon PC \& Stabenow B 1999 Effects of dominance and familiarity on behaviour and plasma stress hormones in growing pigs during social confrontation. Zentralblatt für Veterinärmedizin Reihe A 46 277-292. (doi:10.1046/j.1439-0442. 1999.00216.x)

Rokaeus A, Pruss RM \& Eiden LE 1990 Galanin gene-expression in chromaffin cells is controlled by calcium and protein-kinase signaling pathways. Endocrinology 127 3096-3102. (doi:10.1210/ endo-127-6-3096)

Sato R 2010 Sterol metabolism and SREBP activation. Archives of Biochemistry and Biophysics 501 177-181. (doi:10.1016/j.abb.2010.06.004)

Schimmer BP, Cordova M, Cheng H, Tsao A, Goryachev AB, Schimmer AD \& Morris Q 2006 Global profiles of gene expression induced by adrenocorticotropin in Y1 mouse adrenal cells. Endocrinology 147 2357-2367. (doi:10.1210/en.2005-1526)
Sewer M \& Li DH 2008 Regulation of steroid hormone biosynthesis by the cytoskeleton. Lipids 43 1109-1115. (doi:10.1007/s11745-0083221-2)

Sewer MB, Dammer EB \& Jagarlapudi S 2007 Transcriptional regulation of adrenocortical steroidogenic gene expression. Drug Metabolism Reviews 39 371-388. (doi:10.1080/03602530701498828)

Steckler T 2001 The molecular neurobiology of stress - evidence from genetic and epigenetic models. Behavioural Pharmacology 12 381-427.

Suzuki H, Onaka T, Dayanithi G \& Ueta Y 2010 Pathophysiological roles of galanin-like peptide in the hypothalamus and posterior pituitary gland. Pathophysiology 17 135-140. (doi:10.1016/j.pathophys.2009.03.007)

Turner SP, Farnworth MJ, White IMS, Brotherstone S, Mendl M, Knap P, Penny P \& Lawrence AB 2006 The accumulation of skin lesions and their use as a predictor of individual aggressiveness in pigs. Applied Animal Behaviour Science 96 245-259. (doi:10.1016/ j.applanim.2005.06.009)

Vandesompele J, De Preter K, Pattyn F, Poppe B, Van Roy N, De Paepe A \& Speleman F 2002 Accurate normalization of real-time quantitative RT-PCR data by geometric averaging of multiple internal control genes. Genome Biology 3 RESEARCH 0034. (doi:10.1186/gb-2002-3-7-research0034)

Vinson GP 2003 Adrenocortical zonation and ACTH. Microscopy Research and Technique 61 227-239. (doi:10.1002/jemt.10331)

Vinson GP, Hinson JP \& Toth IE 1994 The neuroendocrinology of the adrenal-cortex. Journal of Neuroendocrinology 6 235-246. (doi:10.1111/j.1365-2826.1994.tb00578.x)

Xing YW, Parker CR, Edwards M \& Rainey WE 2010 ACTH is a potent regulator of gene expression in human adrenal cells. Journal of Molecular Endocrinology 45 59-68. (doi:10.1677/JME-10-0006)

Received in final form 4 January 2011

Accepted 25 January 2011

Made available online as an Accepted Preprint 25 January 2011 